\title{
O QUATERNARISTA GEORGES ZBYSZEWSKI (1909-1999)
}

\author{
G. SOARES DE CARVALHO* \& J. L. CARDOSO**
}

Resumo

Georges Zbyszewski, de nacionalidade francesa, mas de origem russa, nasceu a 22 de Outubro de 1909 e faleceu em Lisboa a 1 de Março de 1999. Esta curta evocação destina-se a homenagear o eminente geólogo, paleontólogo e arqueólogo, que em Portugal desenvolveu quase toda a sua actividade científica.

Palavras-chave: Quaternário, Portugal.

Abstract

Georges Zbyszewski, eminent geologist, palaeontologist and archaeologist of French nationally and Russian birth, deceased, at Lisbon the $1^{* 1}$ of March 1999. In this short evocation, we present the most important scientific contributions of Zbyszewski in Portugal, where he lived since the beginning of the fourties.

Key-words: Quaternary, Portugal.

Georges Zbyszewski, geólogo nascido na Rússia, em Gatchina, a 22 de Outubro de 1909, faleceu em Lisboa, a 1 de Março de 1999.

Zbyszewski, designado entre amigos por Dr. Zby, ou, ainda mais familiarmente, apenas por Zby, foi grande impulsionador e fautor das investigações sobre o Quaternário de Portugal, conforme evidenciam as numerosas publicações sobre este domínio (TEIXEIRA, 1979).

No ano de 1935, G. Zbyszewski deslocou-se, pela primeira vez a Portugal, seguindo a sugestão do Professor Jacques Bourcart, da Faculdade de Ciências de Paris e responsável pelo Laboratório de Geografia Física e Geologia Dinâmica daquela Faculdade, na qual o Doutor Zbyszewski ocupava o lugar de Assistente. A deslocação inscrevia-se na preparação do seu Doutoramento de Estado e tinha por objectivo a observação da geologia das formações litorais quaternárias do Sul do País, em particular no âmbito da recolha de elementos que apoiassem a teoria da «flexura litoral», que aquele Professor formulou a partir de trabalhos de campo realizados em Marrocos e Portugal (BOURCART, 1937) a qual, mais tarde, passou a ser designada por «teoria da flexura continental» (BOURCART, 1950). A intenção de procurar avaliar a teoria de Bourcart, é evidenciada em trabalho de Zbyszewski, quando propôs a substituição da expressão «flexura continental» por «deformação marginal ou litoral». Esta correponderia a «phénomène qui peut être cartographie sur le terrain et celui de zone de déformation marginale ou littorale, pour désigner la zone qui aurait été affectée par l'accident (ZBYSZEWSKI, 1945). Esta ideia de Zbyszewski foi esquecida pela maior parte dos geólogos dedicados ao estudo do Quaternário de Portugal, que preferiram adaptar os resultados das suas investigações a «modelos» fundamentados na suposta estabilidade tectónica do nosso território durante o Quaternário. Porém, tal hipótese, que o próprio ulteriormente também ignorou, perante a mudança global da zona costeira e os múltiplos indicadores de deformação tectónica recente na interface oceano-continente, retomou o seu valor e actualidade.

Em 1940, Georges Zbyszewski tomou posse como geólogo dos Serviços Geológicos, sem contudo abandonar a qualidade de cidadão francês. Passou, então, a consagrar a sua actividade ao estudo da Geologia de Portugal, abarcando grande diversidade de domínios, para além dos estudos de Geologia do Quaternário. A sua qualidade de ser o único geólogo da instituição oficialmente encarregada dos estudos de Geologia do País, fez com que o Doutor George Zbyszewski se entregasse, de forma abnegada, a grande diversidade de temas geológicos, desde os estudos de Geologia Aplicada (no domínio da pesquisa e captação de águas subterrâneas e de minerais não metálicos), passando pelos de índole estratigráfica, vulcanológica, tectónica, sobre tifonismo, Paleontologia, Geologia Regional e Cartografia Geológica (TEIXEIRA, 1979). No âmbito desta última área científica, foram, sem dúvida, os trabalhos de campo desenvolvidos nos arquipélagos dos Açores e da Madeira, que mais gratas recordações lhe deixaram, decorrentes de quase duas dezenas de anos de missões anualmente ali efectuadas e de que resultaram a cartografia de todas as ilhas de ambos os arquipélagos, com excepção da de Porto Santo.

A partir de 1941, Georges Zbyszewski colaborou com o eminente pré-historiador francês Henri Breuil, Membro do Instituto e Professor no Colégio de França. Data dessa época a apresentação conjunta de uma classificação do Paleolítico antigo e médio de Portugal e as relações das respectivas indústrias com as condições geológicas dos respectivos depósitos

* Professor Jubilado da Universidade do Minho.

** Academia Portuguesa da História. Centro de Estudos Geológicos da Faculdade de Ciências e Tecnologia, Universidade Nova de Lisboa. Centro de Estudos Arqueológicos do Concelho de Oeiras - Câmara Municipal de Oeiras, Estrada de Paço de Arcos, 2780 Oeiras. 


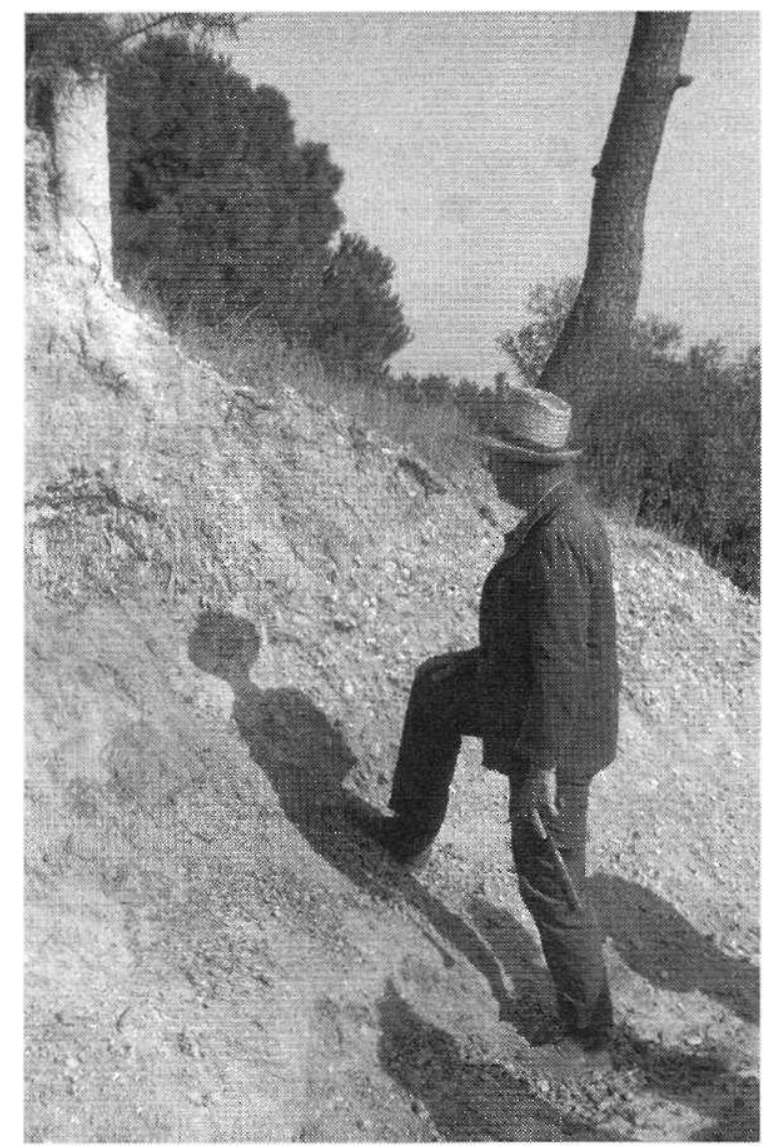

Fig. 1 - Georges Zbyszewski observando depósitos quaternários da Península de Setúbal. (Foto de João Luís Cardoso)
Fig. 1 - Georges Zbyszewski watching a Quaternary deposit in the Setúbal Peninsula. (Photo by João Luís Cardoso)
(BREUIL \& ZBYSZEWSKI, 1942, 1945). Tais estudos pioneiros, cujas conclusões ainda hoje constituem o suporte para muitos dos trabalhos por outrem desenvolvidos, motivaram salutares discussões entre investigadores do passado geológico e humano, como Carlos Teixeira e Orlando Ribeiro, entre outros, sempre na base de franca camaradagem, mantida ao longo dos anos (TEIXEIRA, 1979; RIBEIRO, 1984; DAVEAU, 1993; JORGE, 1999). Com efeito, embora o interesse pela Pré-História já estivesse presente em Georges Zbyszewski antes da chegada de Breuil (deve-se-lhe, por exemplo, a descoberta, pouco tempo antes, das notáveis estações paleolíticas dos arredores de Alpiarça), a verdade é que a valia da sua actividade em tal domínio só se afirmou no decurso da proveitosa colaboração diária, ao longo dos dezassete meses de permanência de Breuil entre nós, de Abril de 1941 a finais do ano seguinte. Após a partida de Breuil, não mais o Doutor Zbyszewski deixou de publicar sobre indústrias paleoliticas, sozinho ou de colaboração, seguindo de forma cuidada, as instruções aprendidas com Breuil; após a reforma por limite de idade, e progressivamente abandonados os trabalhos de terreno que tanto o apaixonaram, continuou a frequentar todos os dias o seu gabinete de trabalho, que conservou nos Serviços Geológicos, doravante na qualidade de colaborador. Ainda menos de dois meses antes de falecer, boa parte do seu tempo útil era dedicado à triagem, classificação e descrição de materiais paleolíticos, que sempre o fascinaram, acima de quaisquer outros; já octogenário, foi co-autor de grosso volume de mais de seiscentas páginas, dedicado a estudo de conjunto dos materiais paleolíticos das ricas jazidas dos arredores de Lisboa, que calcorreou, meio século antes, em companhia de Breuil, desta vez em colaboração com discípulos, formados na por outros denominada «Escola dos Serviços Geológicos» (CARDOSO, ZBYSZEWSKI \& ANDRÉ, 1992).

A sua dedicada e competente actividade científica desenvolvida no nosso País preencheu-lhe todos os momentos, sem que, contudo deixasse de saborear o sentido lúdico da vida; as suas inumeráveis anedotas, 
e os momentos sã camaradagem, passados no campo, com colegas que sempre tratou como Amigos, comprovam a postura sem mácula deste Homem íntegro e sempre disponível, para quem a colaboração e ajuda, desde que requerida, não era favor mas dever. Tal disposição do seu espírito e a competência e autoridade dos seus pareceres, explicam que o Doutor Zbyszewski fosse procurado, para além dos muitos colegas, por uma imensidade de cultores do nosso passado pré-histórico, desejosos de aprenderem com Mestre, ou simplesmente de verem classificados, muitos materiais, arqueológicos ou paleontológicos, por vezes apenas resultantes de colheitas circunstanciais. Sem olhar à respectiva origem, idade, habilitações ou estatuto social, foram muitos os que, nos Serviços Geológicos, assim colmataram muitas lacunas da sua formação, ou tão-somente, saciaram a sua curiosidade e desejo de saber. Foi também essa predisposição que justificou a sua contratação, como Professor Convidado, em 1973, da Faculdade de Ciências da Universidade de Lisboa, onde leccionou, até 1979 , sucessivamente, as disciplinas de Geologia do Quaternário, Estratigrafia e Geohistória e Cartografia Geológica e Fotogeologia Complementar.

Assoberbado pelos múltiplos trabalhos que lhe preenchiam todos os momentos, cumpriu, porém o objectivo que o havia trazido a Portugal, no então já longínquo ano de 1935: em 1958, obteve o Doutoramento de Estado, na Faculdade de Ciências de Paris, em júri ainda integrado pelo Professor Jacques Bourcart, que não desejou abandonar o ensino sem que este seu antigo discípulo concretizasse o primeiro motivo da sua presença em Portugal. A sua dissertação intitulada «Estudo estrutural da área tifónica das Caldas da Rainha (Portugal)», resultou directamente dos trabalhos de cartografia geológica que então desenvolvia na região e foi, de imediato, publicada pelos Serviços Geológicos de Portugal (ZBYSZEWSKI, 1959). Trata-se de memória na qual se analisa o diapirismo das formações mesozóicas e cenozóicas daquela área, e se propõem modelos de evolução estrutural e morfológica da região, susceptíveis de explicar as intensas e complexas modificações tectónicas ali verificadas.

O prestígio que adveio para a França do labor notável deste seu súbdito explica, sucessivamente, o seu agraciamento com a Ordem das Palmas Académicas (1959) e, dez anos depois, com a Ordem Nacional do Mérito de França. Em Portugal, aquando da aposentação por limite de Idade, o então Secretário de Estado da Indústrias Extractivas e Transformadoras, Eng. Joaquim Ferreira do Amaral, fez publicar, em Diário da República, um louvor no qual se realçam os méritos e importância para o País da sua actividade científica. É ainda de destacar a publicação de um volume dedicado ao Doutor Georges Zbyszewski, em Paris, por iniciativa do Prof. Carlos Teixeira e o apoio da Embaixada de França em Lisboa, no qual se reuniram importantes contributos científicos de numerosos Amigos, Colegas e Admiradores.

O seu saber, o seu trato afável e sempre disponível para todos os que o procuravam deixou marcas em muitos de nós, além do exemplo ético e moral do seu trabalho, sempre empenhado e norteado pelos superiores princípios da Verdade Científica, alheio a interesses ou conveniências momentâneas, que cultivou ao longo da sua profícua e longa vida. A impecável bata branca, cuidadosamente engomada que envergava nos Serviços Geológicos, era, sem que disso se apercebesse, a imagem exterior do seu espírito sem mácula, gentil e leal, de uma singeleza cristalina: assim o recordaremos, sempre.

B I B L IOG R A F I A

BOURCART, J. (1937) - Résultats d'ensemble d'une étude du Quaternaire et du Pliocène marin du littoral atlantique du Maroc et du Portugal. Extension possible des hypothèses à l'étude de ces terrains en Méditerranée. Comptes-Rendus du IV Congrès des Géographes et des Ethnographes Slaves. Sofia, p. 57-69.

BOURCART, J. (1938) — La marge continentale. Essai sur les régressions et transgressions marines. Bulletin de la Société Géologique de France. Paris, 89 (5-6), p. 393-474.

BOURCART, J. (1950) - La théorie de la flexure continentale. Compte-Rendu du XVI Congrès International de Géographie (Lisboa, 1949). Lisboa, p. 167-190.

BREUIL, H. \& ZBYSZEWSKI, G. (1942) - Contribution à l'étude des industries paléolithiques du Portugal et de leurs rapports avec la Géologie du Quaternaire. Les principaux gisements des deux rives de l'ancien estuaire du Tage. Comunicações dos Serviços Geológicos de Portugal. Lisboa, 23, 369 p.

BREUIL, H. \& ZBYSZEWSKI, G. (1945) - Contribution à l'étude des industries paléolithiques du Portugal et de leurs rapports avec la Géologie du Quaternaire. Les principaux gisements des plages quaternaires du littoral d'Estremadura et des terrasses fluviales de la vallée du Tage. Comunicações dos Serviços Geológicos de Portugal. Lisboa, 26, 662 p.

CARDOSO, J. L. (1997) - Reconhecidos a Georges Zbyszewski (Actas do I Encontro de Arqueologia da Costa Sudoeste Homenagem a Georges Zbyszewski, Vila do Bispo, 15 a 17 de Novembro de 1991). Setúbal Arqueológica. Setúbal, 11/12, p. 9-16.

CARDOSO, J. L.; ZBYSZEWSKI, G. \& ANDRÉ, M. C (1992) - O Paleolítico do Complexo Basáltico de Lisboa. Estudos Arqueológicos de Oeiras. Oeiras, 3, 645 p.

DAVEAU, S. (1993) - A evolução quaternária da plataforma litoral. O Quaternário em Portugal. Balanço e perspectivas. Lisboa, Associação Portuguesa para o Estudo do Quaternário. Editorial Colibri, p. 17-28.

JORGE, V. Oliveira (1999) - Lembrança do Zby. Trabalhos de Antropologia e Etnologia. Porto, 39 (3/4), p. 11-15.

RIBEIRO, O. (1984) — Les recherches de Georges Zbyszewski sur l'apparition de l'homme, à la lumière de la Philosophie Naturlle. Volume d'hommage au géologue Georges Zbyszewski. Paris, Éditions Recherches sur les Civilisations, p. 55-72.

TEIXEIRA, C. (1979) - Georges Zbyszewski. O Homem e o Cientista. Comunicações dos Serviços Geológicos de Portugal. Lisboa, 65, p. 3-27. 
ZBYSZEWSKI, G. (1940) - Contribution à l'étude du littoral quaternaire du Portugal. Publicações do Museu e Laboratório Mineralógico e Geológico da Faculdade de Ciências do Porto. Porto, 15, $13 \mathrm{p}$.

ZBYSZEWSKI, G. (1945) - La notion classique de «flexure» et celle des déformations marginales. Boletim da Sociedade Geológica de Portugal. Porto, 4 (3), p. 175-188.
ZBYSZEWSKI, G. (1959) - Étude structurale de l'aire typhonique de Caldas da Rainha (Portugal). Tese de Doutoramento de Estado apresentada à Faculdade de Ciências da Universidade de Paris. Memórias dos Serviços Geológicos de Portugal. Lisboa, Nova Série, $3,182 \mathrm{p}$.

ZBYSZEWSKI, G. (1966) — Adieu, L'Abbé Breuil/ In Memoriam do Abade Henri Breuil. Revista da Faculdade de Letras de Lisboa. Lisboa, Série III, 10, p. 361-373. 